\title{
On the Steadiness and Instability of the Intermediate Western Boundary Current between $24^{\circ}$ and $18^{\circ} \mathrm{S}$
}

\author{
Dante C. Napolitano and Ilson C. A. Da Silveira \\ Instituto Oceanográfico, Universidade de São Paulo, São Paulo, Brazil \\ CESAR B. RochA \\ Woods Hole Oceanographic Institution, Woods Hole, Massachusetts \\ GLENN R. FLIERL \\ Massachusetts Institute of Technology, Cambridge, Massachusetts \\ Paulo H. R. CALiL \\ Helmholtz-Zentrum Geesthacht, Geesthacht, Germany \\ RENATO P. MARTINS \\ Centro de Pesquisas e Desenvolvimento Leopoldo Américo Miguez de Mello, Rio de Janeiro, Brazil
}

(Manuscript received 14 January 2019, in final form 24 September 2019)

\begin{abstract}
The Intermediate Western Boundary Current (IWBC) transports Antarctic Intermediate Water across the Vitória-Trindade Ridge (VTR), a seamount chain at $\sim 20^{\circ} \mathrm{S}$ off Brazil. Recent studies suggest that the IWBC develops a strong cyclonic recirculation in Tubarão Bight, upstream of the VTR, with weak time dependency. We herein use new quasi-synoptic observations, data from the Argo array, and a regional numerical model to describe the structure and variability of the IWBC and to investigate its dynamics. Both shipboard acoustic Doppler current profiler (ADCP) data and trajectories of Argo floats confirm the existence of the IWBC recirculation, which is also captured by our Regional Oceanic Modeling System (ROMS) simulation. An "intermediate-layer" quasigeostrophic (QG) model indicates that the ROMS time-mean flow is a good proxy for the IWBC steady state, as revealed by largely parallel isolines of streamfunction $\bar{\psi}$ and potential vorticity $\bar{Q} ;$ a $\bar{\psi}-\bar{Q}$ scatter diagram also shows that the IWBC is potentially unstable. Further analysis of the ROMS simulation reveals that remotely generated, westward-propagating nonlinear eddies are the main source of variability in the region. These eddies enter the domain through the Tubarão Bight eastern edge and strongly interact with the IWBC. As they are advected downstream and negotiate the local topography, the eddies grow explosively through horizontal shear production.
\end{abstract}

\section{Introduction}

North of $28^{\circ} \mathrm{S}$, off the Brazilian coast, the Antarctic Intermediate Water (AAIW) flow bifurcation sets up an equatorward-flowing Intermediate Western Boundary Current (IWBC), opposing the Brazil Current (BC) direction (Boebel et al. 1997, 1999; Legeais et al. 2013). The IWBC was first predicted by Stommel (1965) in his

\footnotetext{
Corresponding author: Dante C. Napolitano, dante.napolitano@ usp.br
}

seminal book The Gulf Stream as part of the South Atlantic meridional overturning circulation (MOC). Observational evidence of the IWBC and the AAIW transport, however, dates to the late 1990s and early 2000s (Boebel et al. 1997; Müller et al. 1998; Boebel et al. 1999; Schmid et al. 2000; da Silveira et al. 2004; Campos 2006). More recent investigations define the IWBC as an equatorward jet, spanning from $\sim 400 \mathrm{~m}$ to greater than $\sim 1600$-m depth, that carries about $6 \mathrm{~Sv}\left(1 \mathrm{~Sv} \equiv 10^{6} \mathrm{~m}^{3} \mathrm{~s}^{-1}\right)$ of intermediate waters (da Silveira et al. 2008; Rocha et al. 2014; Biló et al. 2014). The most well-established of 


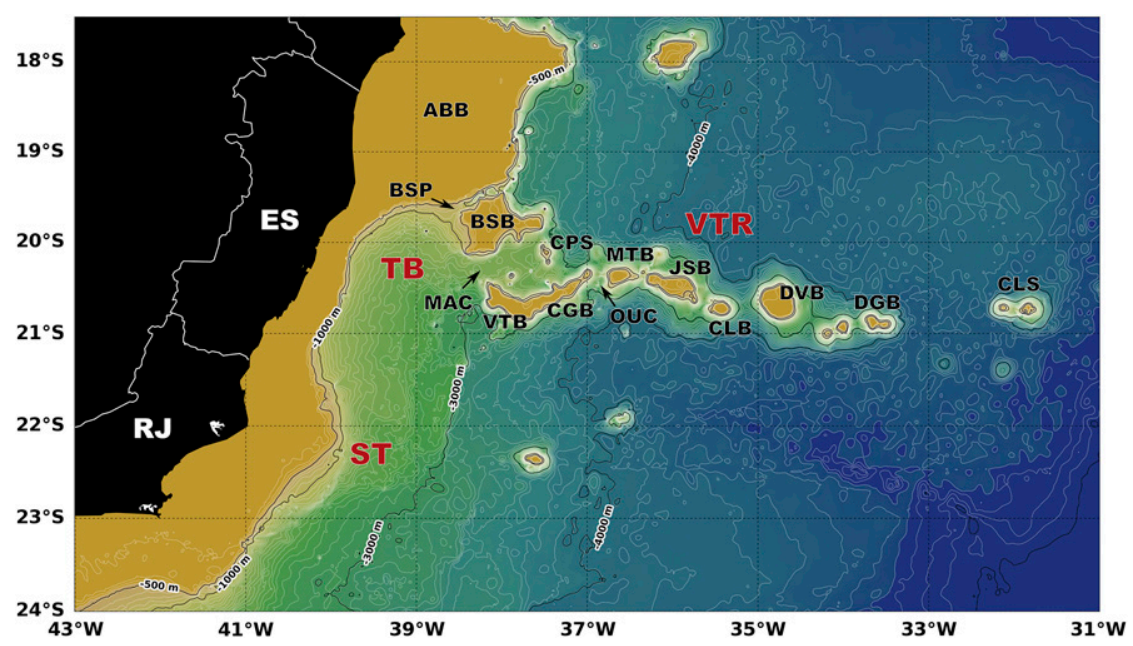

FIG. 1. The study area and main topographic features: Cape São Tomé (ST), Tubarão Bight (TB), and Vitória-Trindade Ridge (VTR). Other keys represent the banks: Abrolhos Bank (ABB), Besnard Bank (BSB), Vitória Bank (VTB), Congress Bank (CGB), Montague Bank (MTB), Jaseur Bank (JSB), Columbia Bank (CLB), Davis Bank(DVB), and Dogaressa Bank (DGB); seamounts: Champlaim Seamount (CPS) and Columbia Seamount (CLS); and channels: Besnard Passage(BSP), Main Channel (MAC), and Outer Channel (OUC) of the submarine chain. Bathymetry used is from the General Bathymetric Chart of the Oceans (GEBCO; Weatherall et al. 2015).

those water masses is the AAIW, traced oceanwide by its low-salinity core (Wüst 1935) and surface-referenced potential density between 1027.1 and $1027.4 \mathrm{~kg} \mathrm{~m}^{-3}$ (Tsuchiya et al. 1994). This northward volume flux of intermediate water closes the MOC, and thus the AAIW is an essential component of the climate system (Rintoul 1991; Schmitz 1995).

The Vitória-Trindade Ridge (VTR)—a quasi-zonal seamount chain at $20^{\circ} \mathrm{S}$-is a western boundary current rendezvous point, where the $\mathrm{BC}$ and IWBC meet important topographic constraints and are forced to go through the banks, generating mesoscale (and most likely submesoscale) structures. For the IWBC, three main obstacles are the probable causes for the current to meander: Cape São Tomé, Tubarão Bight, and the VTR topographic features (Fig. 1).

Mesoscale variability in the IWBC has been explored in the last decade by the works of da Silveira et al. (2008), Mano et al. (2009), Legeais et al. (2013), and Costa et al. (2017). Da Silveira et al. (2008) show baroclinic instability as the main forcing mechanism for the IWBC unstable meanders. Mano et al. (2009) showed that the BC-IWBC meandering starts at the IWBC and transfers energy from intermediate to upper layers. Legeais et al. (2013) presented evidence of abundant mesoscale motions at the IWBC level north of the VTR. Costa et al. (2017) described a tight cyclonic recirculation within Tubarão Bight, which is likely to be either permanent or semipermanent. Previous results on the IWBC include current-meter mooring velocity measurements (Evans and Signorini 1985; Müller et al. 1998; Costa et al. 2017), numerical models (da Silveira et al. 2004, 2008; Costa et al. 2017), CTD-derived velocities (da Silveira et al. 2004, 2008), and Lagrangian studies (Boebel et al. 1999; Schmid and Garzoli 2009; Legeais et al. 2013; Costa et al. 2017); however, few have solely focused on the IWBC.

Given the recent findings of Costa et al. (2017) on the stationarity and supposed quasi-steadiness of the Tubarão Bight recirculation and its impact on the dynamics of the IWBC, we formulate the following questions: (i) What is the basic state of the IWBC off southeast Brazil $\left(24^{\circ}-18^{\circ} \mathrm{S}\right)$, and how is this basic state related to the temporal-mean spatial pattern depicted from observations and numerical simulations? (ii) Which mechanisms drive the observed mesoscale variability along the IWBC path?

\section{The intermediate circulation between $24^{\circ}$ and $18^{\circ} \mathrm{S}$}

\section{a. Quasi-synoptic observations}

We employ recent quasi-synoptic observations obtained in the "Marine Environment Characterization of the Espírito Santo Sedimentary Basin" Experiment (hereafter AMBES), conducted through a partnership of the Oceanographic Institute of the University 

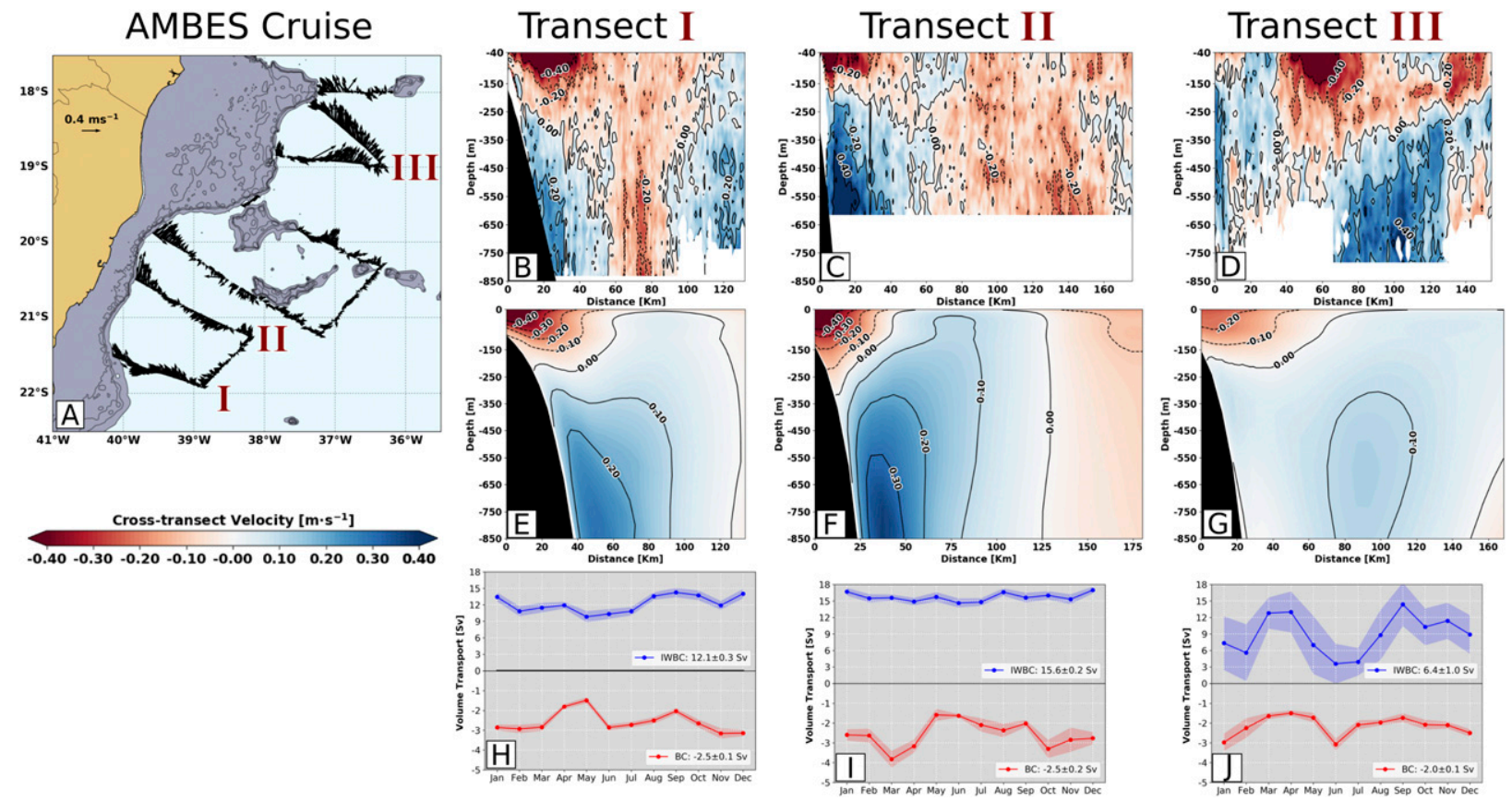

FIG. 2. (a) Horizontal circulation pattern at $600 \mathrm{~m}$ (therefore within the depth range of the IWBC core layer) from shipboard ADCP data obtained during the AMBES cruise (5-18 Oct 2012; black arrows). (b)-(d) Shipboard ADCP vertical sections from three transects (I, II, and III) of the AMBES campaign. (e)-(g) ROMS 2-month averages (September-October) for the 7 years of simulation at transects I, II, and III. Solid (dashed) black contours represent equatorward (poleward) velocities. (h)-(j) Monthly mean transport and associated error for the BC (red line) and IWBC (blue line) for the ROMS simulation at transects I, II, and III.

of São Paulo (IOUSP) and Petróleo Brasileiro S.A. (Petrobras). The spring 2012 AMBES cruise obtained direct velocity measurements with a 38-kHz RDI shipboard acoustic Doppler current profiler (ADCP), which sampled the upper $650-850 \mathrm{~m}$ of the water column. We processed the shipboard ADCP data following the guidelines of Firing et al. (1995). We used 10-min ensemble averages and discarded data with a return signal (the so-called "percent good") below $85 \%$. To the best of our knowledge, these are the first quasi-synoptic velocity observations within the IWBC in the VTR region.

Figure 2a displays ADCP velocity observations at $600 \mathrm{~m}$ along the ship track, collected during the AMBES cruise. Figures $2 \mathrm{~b}-\mathrm{d}$ show cross-transect velocity vertical sections for three selected transects (I, II, and III). Transect I in Fig. 2b shows a typical BC-IWBC system pattern: the opposing flows of the southward-flowing $\mathrm{BC}$ and the northward-flowing IWBC on the Brazilian southeast continental slope (e.g., Boebel et al. 1999; da Silveira et al. 2008; Lima et al. 2016). The IWBC, which is apparently meandering in transect I, presents a core speed of $0.25 \mathrm{~m} \mathrm{~s}^{-1}$ - the weakest measured during the cruise. (Although treated here as a meander, without additional data south of transect I we cannot rule out other possibilities, for example, the presence of an isolated eddy by the IWBC.) The meandering of the
BC-IWBC jet near Cape São Tomé and Cape Frio $\left(\sim 23.5^{\circ} \mathrm{S}\right)$ was also investigated by da Silveira et al. (2008), Mano et al. (2009), and Rocha et al. (2014).

Figure $2 \mathrm{c}$ shows that the intermediate-level circulation inside Tubarão Bight resembles a cyclone structure. The lobe adjacent to the continental margin exhibits velocities up to $0.50 \mathrm{~m} \mathrm{~s}^{-1}$. This pattern in transect II confirms the description by Costa et al. (2017): an IWBC cyclonic recirculation within Tubarão Bight. These authors used data from two current-meter moorings, together with Argo float trajectories and the output of a numerical model. Their findings indicated that this recirculation weakens the northward flow that crosses the VTR, and consequently intensifies the flow downstream along the western boundary. This intensification of the IWBC inside Tubarão Bight was also described by Legeais et al. (2013). Moreover, Costa et al. (2017) observed the shoaling of the IWBC within the bight, using mooring velocity data, with a mean velocity reversal depth of $370 \mathrm{~m}$, but with instantaneous reversals at $150 \mathrm{~m}$. As for the BC, our observations depict a $\sim 200$-m-deep jet confined to the shelf break.

The IWBC crosses the VTR through a narrow channel between the Besnard and Vitória-Congress Banks, which is the main IWBC path out of Tubarão Bight (Legeais et al. 2013; Costa et al. 2017). Transect III in 
Fig. 2d captures the main branch of the intermediate current reorganized downstream of the seamounts region, where the IWBC shows strong instantaneous velocities (up to $0.48 \mathrm{~m} \mathrm{~s}^{-1}$ ) and the BC is detached from the slope.

The features presented in Figs. 2a-d are consistent with what has been described by da Silveira et al. $(2004,2008)$, Legeais et al. (2013), and Costa et al. (2017), namely, an organized IWBC off Cape São Tomé (transect I), a strengthened and recirculating IWBC within Tubarão Bight (transect II), and an IWBC branch reorganizing north of the VTR (transect III). However, the data are restricted to a few transects and occupied over a month. These quasi-synoptic observations include a number of transients, and thus cannot be used to assess the stationarity of the IWBC flow and its recirculation.

\section{b. The Regional Ocean Modeling Experiment}

To fully examine the steadiness and stability of the circulation within the AAIW layer in the study area, long time series of potential density and velocity are required. Given the paucity of such observations in the region, we opt to answer the questions posed herein with the aid of a regional circulation experiment output. We use the Regional Oceanic Modeling System (ROMS) with a configuration for the western portion of the South Atlantic Ocean $\left(41^{\circ} 16^{\prime}-\right.$ $\left.10^{\circ} 01^{\prime} \mathrm{S}, 62^{\circ} 34^{\prime}-19^{\circ} 49^{\prime} \mathrm{W}\right)$. The model has a horizontal resolution of $6 \mathrm{~km}$ and 30 vertical levels in terrain-following coordinates, which suffices to resolve mesoscale eddies in the region. The simulation was initialized on 1 January 2000 with temperature and salinity fields from the Simple Ocean Data Assimilation (SODA) project and ran for 11 years subject to SODA fields on the open boundaries, with a spinup time of 6 years. Our analysis below uses data spanning the last 7 years of the simulation, in which the dynamical fields were statistically equilibrated. The model is forced by climatological monthly surface wind and heat fluxes from QuikSCAT and COADS, respectively. We emphasize that our goal in using a model forced with monthly mean climatologies of wind and heat fluxes is to obtain a consistent dynamical simulation of the area rather than a hindcast simulation of the observed events.

Figures $2 \mathrm{e}-\mathrm{g}$ present the September-October crosstransect velocity averages for transects I, II, and III over the 7 years of ROMS output. In Figs. 2h-j, we also show 7-yr monthly averages of transports of the $\mathrm{BC}$ and the IWBC.

The model simulated the typical BC-IWBC vertical structure in transect I (Fig. 2e). The modeled IWBC transport shows no significant seasonal variability and is consistent with the simulation in Costa et al. (2017). Our simulated $\mathrm{BC}$ transport displays two annual maxima (2-H), while Schmid and Majumder (2018) reported one (summer) or two (summer and spring) annual maxima.
The observed BC-IWBC structure in transect II is qualitatively well reproduced by ROMS. As in the ADCP data, the simulated IWBC is strongest inside Tubarão Bight; this enhanced transport is present in the model, although the recirculating branch is not well captured by the simulation's transect II (cf. Figs. 2c,f). The recirculation in ROMS is more confined within Tubarão Bight than the one inferred from Argo, as well as displaced northward (more on this in the next section). The modeled BC displays large transport monthly variations in transect II (Fig. 2i), most likely associated with the $\mathrm{BC}$ negotiating topography while crossing the VTR (cf. Costa et al. 2017).

The ROMS 2-month average in Fig. 2g depicts a weak and shallow BC, with a transport of $2 \mathrm{~Sv}$. Soutelino et al. (2011) characterized the BC north of the VTR as a shallow and eddy-dominated flow, consistent with our simulation. Just north of the VTR, the simulated IWBC is highly variable on a monthly time scale, alternating northward and eastward flows. The IWBC transport is largest in months of predominantly northward flow (March, April, and September); on the other hand, transport through transect III is nearly zero when the IWBC veers eastward (February, June, and July) (see Fig. 2j). Although apparently overestimated by our simulation, this eastward flow north of the VTR was previously inferred by Wienders et al. (2000) and observed by Schmid and Garzoli (2009), who qualitatively associated it with eastward penetrations of AAIW. Legeais et al. (2013) suggested a link between the weakening of the IWBC north of $20^{\circ} \mathrm{S}$ and an exchange of AAIW between the western boundary and the ocean interior.

Both BC and IWBC transports in our ROMS simulation match those simulated by Costa et al. (2017). The eastward flow north of the VTR is not present in the simulation in Costa et al. (2017); this is the main inconsistency between the two models. In a literature survey presented in Table 1 , we detail a comparison between previous estimates of the BC-IWBC transports and our study.

\section{c. The Argo float climatology}

Given that the parking depths of Argo floats lie within the IWBC domain, we can use float trajectories to characterize the time-mean velocity pattern near the VTR $\left(26^{\circ}-16^{\circ} \mathrm{S}, 43^{\circ}-32^{\circ} \mathrm{W}\right.$ ). We obtained the Argo dataset (Argo 2019) from the AOML database (http://tds0.ifremer.fr/ thredds/catalog/CORIOLIS-ARGO-GDAC-OBS/aoml/ catalog.html) and selected floats that entered the domain from January 2000 through April 2019, drifting within the IWBC with parking depths between 600 and $1100 \mathrm{~m}$.

We determined the location and period of an Argo cycle by the middle point of the float trajectory and its 
TABLE 1. Comparison between the AMBES cruise, ROMS outputs, and literature. ADCP transports are restricted to the depth range presented in Figs. 2b-d. ROMS transports are averaged for the simulation period (7 years) in virtually the same ADCP transect position. Positive (negative) values indicate northward (southward) volume transport. REMO is the abbreviation for Rede de Modelagem e Observação Oceanogáfica, an initiative of the Brazilian Navy and Petróleo Brasileiro S.A. based on a 1/12 $2^{\circ}$ Hybrid Coordinate Ocean Model run.

\begin{tabular}{|c|c|c|c|}
\hline $\mathrm{BC}$ & Data & Latitude (S) & Transport (Sv) \\
\hline Schmid and Majumder (2018) & Argo/SSH & $24^{\circ}$ & -2.3 \\
\hline da Silveira et al. (2004) & Pegasus profiler & $23^{\circ}$ & $-5.6 \pm 1.4$ \\
\hline Mata et al. (2013) & Hydrographic & $22^{\circ}$ & -2.3 \\
\hline This study (transect I) & ADCP & $21.5^{\circ}$ & -2.4 \\
\hline This study (transect I) & ROMS & $21.5^{\circ}$ & $-2.5 \pm 0.1$ \\
\hline This study (transect II) & ADCP & $20.5^{\circ}$ & 1.0 \\
\hline This study (transect II) & ROMS & $20.5^{\circ}$ & $-2.5 \pm 0.2$ \\
\hline Evans et al. (1983) & Hydrographic & $20^{\circ}$ & 3.8 \\
\hline Stramma et al. (1990) & Hydrographic & $20^{\circ}$ & 1.6 \\
\hline This study (transect III) & $\mathrm{ADCP}$ & $19^{\circ}$ & 4.5 \\
\hline This study (transect III) & ROMS & $19^{\circ}$ & $-2.0 \pm 0.1$ \\
\hline IWBC & Data & Latitude (S) & Transport (Sv) \\
\hline Boebel et al. (1999) & Floats & $28^{\circ}-2^{\circ}$ & $4.0 \pm 2.0$ \\
\hline Müller et al. (1998) & Current meter & $23^{\circ}$ & 1.3 \\
\hline da Silveira et al. (2004) & Pegasus profiler & $23^{\circ}$ & $3.6 \pm 0.8$ \\
\hline da Silveira et al. (2008) & Hydrographic & $23^{\circ}$ & 3.0 \\
\hline Costa et al. (2017) & REMO & $22^{\circ}$ & $12.0 \pm 5.0$ \\
\hline This study (transect I) & ADCP & $21.5^{\circ}$ & 2.4 \\
\hline This study (transect I) & ROMS & $21.5^{\circ}$ & $12.0 \pm 0.3$ \\
\hline This study (transect II) & $\mathrm{ADCP}$ & $20.5^{\circ}$ & 3.7 \\
\hline This study (transect II) & ROMS & $20.5^{\circ}$ & $12.0 \pm 0.2$ \\
\hline Schmid and Garzoli (2009) & Floats & $20^{\circ}$ & 10 \\
\hline This study (transect III) & ADCP & $19^{\circ}$ & 6.5 \\
\hline This study (transect III) & ROMS & $19^{\circ}$ & $6.4 \pm 1.0$ \\
\hline
\end{tabular}

duration, respectively. (Fig. 3 shows the spatial distribution of the number of Argo observations on a $12.5 \mathrm{~km} \times 12.5 \mathrm{~km}$ grid.) We identify each Argo cycle in the float trajectory and treat it as an independent sample. In doing so, we eliminate surface drift during data transmission and ignore the short profiling time (Park et al. 2005). Also, floats that dwelt for too short ( $<5$ days) or too long ( $>15$ days) in their parking depths were removed from the analysis. These criteria yield 5503 cycles from 90 floats that occupied the region, with an average cycle of $9.6 \pm 0.18$ days.

We estimate horizontal velocity $(u$ and $v)$ at the parking depth from the position difference between the end and the beginning of each cycle divided by the average parking time (Lebedev et al. 2007). We then interpolate the parking-depth velocity onto a $12.5 \mathrm{~km} \times 12.5 \mathrm{~km}$ grid. Figure 3 shows that the Argo array presents good coverage in the region compared to previous datasets, but the number of Argo cycles per grid point is still small, particularly north of the VTR.

We calculate the streamfunction $\bar{\psi}$ by solving the elliptic equation

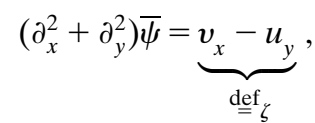

where

$$
(\bar{u}, \bar{v})=\left(-\bar{\psi}_{y}, \bar{\psi}_{x}\right)
$$

We solve for the streamfunction $\bar{\psi}$ given the vorticity $v_{x}-u_{y}$ in (1) using a Fourier spectral method:

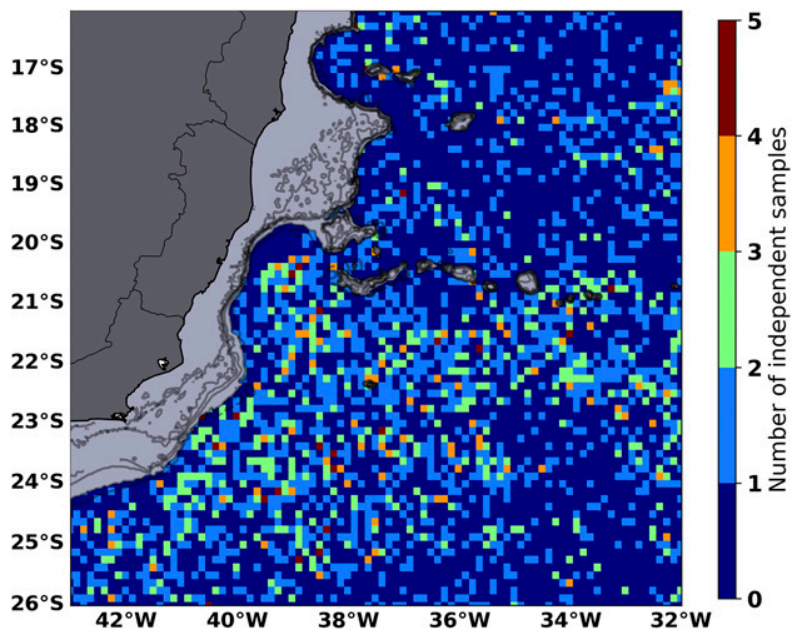

FIG. 3. Spatial distribution of the number of samples per cell in the $12.5 \mathrm{~km} \times 12.5 \mathrm{~km}$ grid from 5503 Argo cycles used to estimate the Argo-derived velocity. 


$$
\hat{\psi}=\left\{\begin{array}{cl}
-\frac{\hat{\zeta}}{k^{2}+l^{2}}, & k^{2}+l^{2} \neq 0, \\
0, & k=l=0,
\end{array}\right.
$$

where $\hat{\psi}$ is the Fourier transform of the streamfunction, $\hat{\zeta}$ is the Fourier transform of the relative vorticity, and $(k, l)$ is the wavevector. Before calculating $\hat{\zeta}$, we periodize $\zeta$ using mirror reflections to obtain a doubly periodic field (e.g., Isern-Fontanet et al. 2006). Next, we smooth $\bar{\psi}$ with a Gaussian filter (1.5 standard deviations) and enforce zero streamfunction in regions shallower than $700 \mathrm{~m}$. Finally, we ensure that the gridded velocity preserves the variance of the float-derived velocity by multiplying the Argo-derived velocity by $\sigma_{a} / \sigma_{g}$, where $\sigma_{a}$ is the RMS Argo velocity and $\sigma_{g}$ is the RMS nondivergent velocity. Horizontal scales of the Argo gridded velocity $(12.5 \mathrm{~km})$ and the sampling time scales of the Argo array ( $\sim 10$ days) yield approximately geostrophic velocities, with maximum velocities $\left(\sim 0.30 \mathrm{~m} \mathrm{~s}^{-1}\right) 12 \%$ weaker than the maximum instantaneous Argo velocities $\left(\sim 0.34 \mathrm{~m} \mathrm{~s}^{-1}\right)$.

The Argo-derived flow (Fig. 4a) depicts the IWBC flowing northward along the continental slope with maximum speed of $\sim 0.30 \mathrm{~m} \mathrm{~s}^{-1}$. Argo climatological speeds are close to the Costa et al. (2017) mooring time averages. Müller et al. (1998) analyzed moorings in the region, with mean velocities ranging from 6 to $21 \mathrm{~cm} \mathrm{~s}^{-1}$, both in the same ballpark as our estimates. Near the Tubarão Bight northern limit, the flow splits into two branches, one exiting the bight flowing northward (Legeais et al. 2013; Costa et al. 2017), and the other veering southward and forming a cyclonic recirculation. This Argo climatology does not display an intermediate flow through the Besnard Passage, in contrast to the strong synoptic flow observed in the AMBES ADCP survey (Fig. 2a) and two RAFOS float trajectories that exited the bight through this passage (Legeais et al. 2013).

\section{d. Comparison between Argo float climatology and $R O M S$}

The horizontal mean velocity of our ROMS simulation is qualitatively consistent with the Argo intermediate circulation pattern (cf. Figs. 4a and 4b). ROMS maximum velocities are $25 \%$ larger than maximum Argo velocities, and these quantitative differences are likely due to the smoothing nature of the trajectorybased Argo velocity (an average over 9.6 days and $12.5 \mathrm{~km} \times 12.5 \mathrm{~km}$ ) compared to ROMS's daily snapshots on a $6-\mathrm{km}$ horizontal grid.

According to the Argo estimates, about $58 \%$ of the flow that enters Tubarão Bight at Cape São Tomé exits

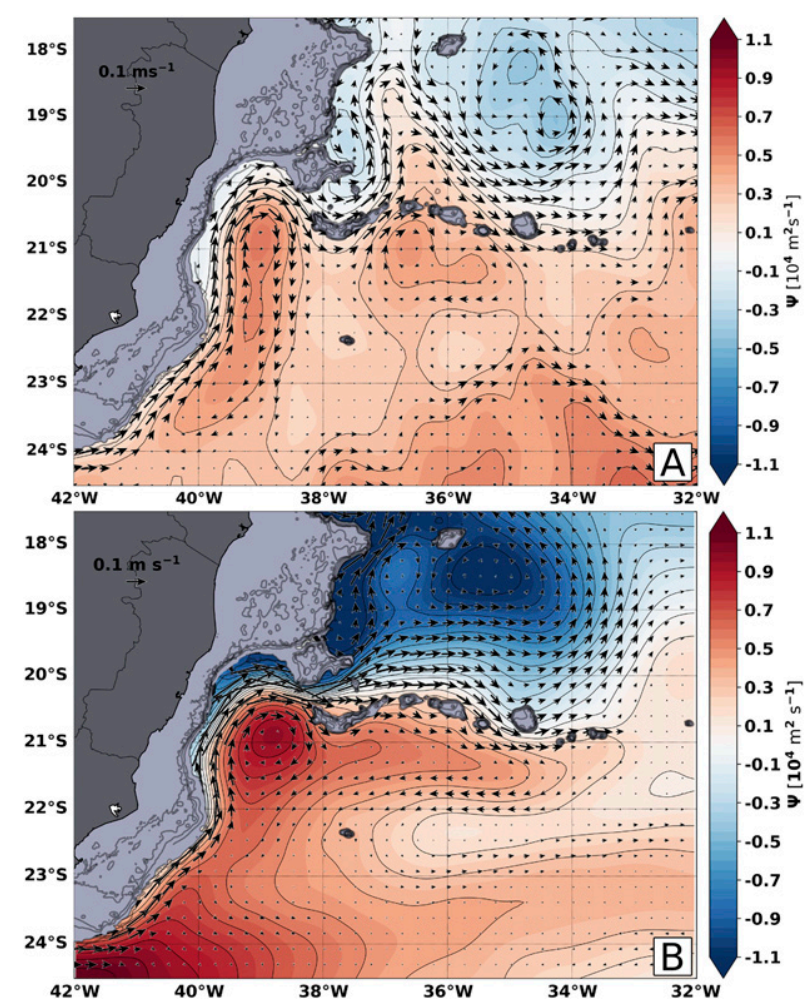

FIG. 4. (a) Streamfunction (contours) and nondivergent velocity (arrows) inferred from Argo displacements within each cycle for the 2000-19 period in the AAIW layer. The grid resolution is $1 / 8^{\circ}$. (b) Streamfunction (contours) and nondivergent velocity (arrows) calculated from ROMS for the 2000-06 period in the AAIW layer. The grid resolution is $1 / 16^{\circ}$.

it through the main channel; the remaining $42 \%$ recirculates. In ROMS, $70 \%$ of the flow exits the bight through the main channel, and the remaining $30 \%$ recirculates. The flow that crosses the ridge through the main channel bifurcates: $58 \%$ flows north and $42 \%$ veers eastward. Similar to ROMS, Argo presents an eastward flow between $36^{\circ}$ and $34^{\circ} \mathrm{W}$. But Argo does not clearly depict a zonally elongated recirculation, which in ROMS extends east of Tubarão Bight and around the VTR for $400 \mathrm{~km}$. As mentioned earlier, our simulation may be overestimating this eastward flow and, owing to paucity of observations, care must be taken in interpreting model results north of the VTR [see Fig. 3 and the discussion of data density in Schmid and Garzoli (2009)].

Two mesoscale features appear in the lee of the VTR between $\sim 18^{\circ}$ and $20^{\circ} \mathrm{S}$ : a cyclone centered at $\sim 37^{\circ} \mathrm{W}$ and a larger anticyclone at $\sim 35^{\circ} \mathrm{W}$, off the Abrolhos Bank. Legeais et al. (2013) noted that some floats stalled for a long time off the Abrolhos Bank. Those floats were probably trapped by these features. 


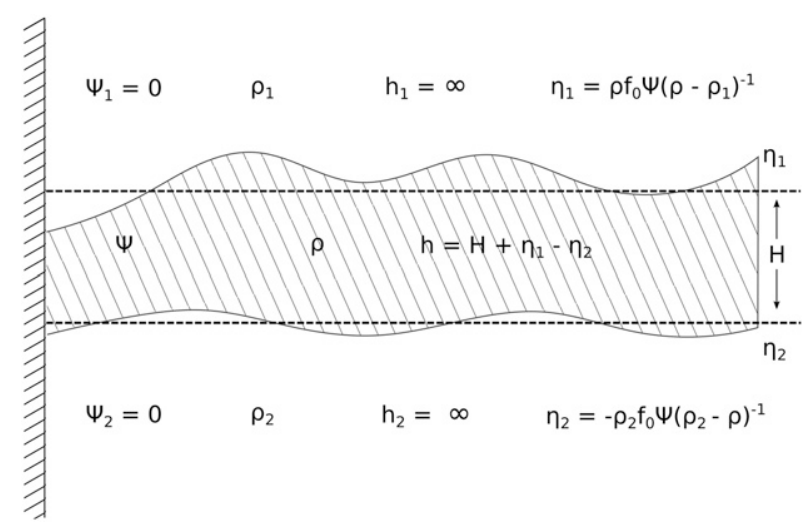

FIG. 5. Representation of the intermediate-layer model configuration. Both upper and lower layers are infinite and have no motion. $\rho$ represents density $\left(\mathrm{kg} \mathrm{m}^{-3}\right) ; H$ represents the mean layer depth, and $\eta$ represents the upper and lower boundaries.

\section{The IWBC steady state in the vicinity of the VTR}

In the previous section, we show that mesoscale features appear in the time-mean IWBC flow. Are these time-mean features the result of strong unsteady eddies? Or are they permanent structures caused by the topographic steering of the IWBC?

If the mesoscale features are steady, then the flow should occur along potential vorticity contours (e.g., Bretherton and Haidvogel 1976). On the other hand, mean potential vorticity contours cross streamlines when mesoscales features are unsteady (e.g., Vallis 2017). To address this question, we formulate an intermediatelayer quasigeostrophic model within the AAIW layer (1027.1-1027.4 $\mathrm{kg} \mathrm{m}^{-3}$; Tsuchiya et al. 1994). We diagnose quasigeostrophic streamfunction $\psi$ and potential vorticity $Q$, and investigate the properties of the mean flow using $\psi-Q$ scatter diagrams (Bretherton and Haidvogel 1976; Read et al. 1986).

\section{a. Model formulation}

The intermediate-layer model consists of three immiscible layers, with the intermediate layer-which contains all the flow-sandwiched by two stagnant, semi-infinite layers with $\psi=0$ (see Fig. 5). The potential vorticity in the model is given by

$$
\begin{aligned}
Q_{1} & =\beta y, \\
Q & =\left(\nabla^{2}-\frac{1}{R_{d}^{2}}\right) \psi+\beta y, \\
Q_{2} & =\beta y,
\end{aligned}
$$

where $\beta$ is the planetary potential vorticity gradient, and $R_{d}$ is the deformation radius (details in the estimation of $g^{\prime}$ are given in appendix A),

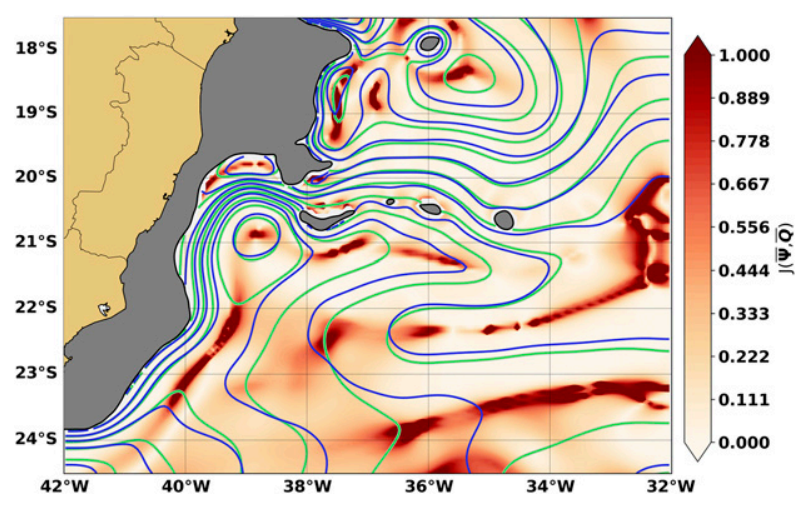

FIG. 6. The $\bar{\psi}$ vs $\bar{Q}$ mean state for the IWBC, averaged for the AAIW layer, between the 1027.1 and $1027.4 \mathrm{~kg} \mathrm{~m}^{-3}$ isopycnals. Blue lines represent streamfunction $\bar{\psi}$, green lines represent potential vorticity $\bar{Q}$, and background colors represent the normalized Jacobian $J(\bar{\psi}, \bar{Q}) /(|\nabla \bar{\psi}||\nabla \bar{Q}|)$.

$$
R_{d}^{2} \stackrel{\text { def }}{=} \underbrace{\left(\frac{\rho-\rho_{1}}{\rho_{2}-\rho_{1}}\right)\left(\frac{\rho_{2}-\rho}{\rho}\right)}_{\text {def } g^{\prime} / g} \frac{g H}{f_{0}^{2}} .
$$

The planetary vorticities $Q_{1}$ and $Q_{2}$ have no dynamical role in the system (da Silveira and Flierl 2002). The total potential vorticity $Q$ and streamfunction $\psi$ can be split into a steady solution and a time-dependent perturbation:

$$
\begin{aligned}
\psi(x, y, t) & =\bar{\psi}(x, y)+\tilde{\psi}(x, y, t), \\
Q(x, y, t) & =\bar{Q}(x, y)+\tilde{Q}(x, y, t) .
\end{aligned}
$$

We are interested in the steady part of the flow, particularly the relation between $\bar{\psi}$ and $\bar{Q}$. As the flow enters a "free-mode" configuration, $\bar{\psi}$ and $\bar{Q}$ become correlated (Bretherton and Haidvogel 1976):

$$
\bar{Q}=\bar{Q}(\bar{\psi}) .
$$

From (8) follows the definition

$$
J(\bar{\psi}, \bar{Q}) \stackrel{\text { def }}{=} \bar{\psi}_{x} \bar{Q}_{y}-\bar{\psi}_{y} \bar{Q}_{x}=0 .
$$

To assess whether the mean IWBC satisfies the zero Jacobian condition (9), we use the time-mean flow defined as a 7-yr average of the ROMS output within the AAIW layer.

\section{b. The steady solution}

Figure 6 shows the streamfunction $\bar{\psi}$ (Fig. 4b) overlaid on contours of quasigeostrophic potential vorticity $\bar{Q}$ in (4), both calculated from ROMS; colors represent the Jacobian in (9) normalized by $|\nabla \bar{\psi}||\nabla \bar{Q}|$. 




FIG. 7. The $\bar{\psi}-\bar{Q}$ scatter diagram for the IWBC, averaged for the AAIW layer, between the 1027.1 and $1027.4 \mathrm{~kg} \mathrm{~m}^{-3}$ isopycnals. $I$ is the free-mode departure index.

The quasigeostrophic potential vorticity is nearly parallel to the streamfunction. Hence, the Jacobian is very small within the IWBC on the continental slope and in the recirculation within Tubarão Bight, indicating a steady geostrophic flow. However, it is fairly large in patches where the current is known to meander vigorously (see Fig. 2) and in regions where the mean current is weak. This basic state shows the main path by which AAIW is transported equatorward to join the MOC downstream of our study region.

Also about the IWBC steadiness, we observe a quasilinear relation between $\bar{\psi}$ and $\bar{Q}$ (Fig. 7), which confirms that the mean flow is largely steady, and therefore the time-mean potential vorticity can be calculated from the time-mean flow using the relation

$$
\bar{Q}(\bar{\psi})=\alpha \bar{\psi},
$$

where $\alpha$ is a constant. A linear fit gives $\alpha=-3.84 \times$ $10^{-9} \mathrm{~m}^{-2}$. Small curvatures in Fig. 7 hint at two distinct regions (northern and southern parts of the domain) and a slightly nonlinear $\bar{Q}(\bar{\psi})$.

\section{c. Stability of the steady state}

The scatter about the straight line $\bar{Q}=\alpha \bar{\psi}$ quantifies the steadiness of the flow. In particular, Read et al. (1986) define an index of departure from the free-form mode:

$$
I \stackrel{\text { def }}{=} \frac{A}{\Delta \psi \Delta Q}=\frac{\text { Area enclosed on the } \psi-Q \text { diagram }}{\text { Area of the circumscribing rectangle }} .
$$

A purely steady state has no scatter, and therefore $I=0$, while a strong unsteady flow presents large scatter, with $I$ approaching 1 . In Fig. 7, $I=0.08$ indicating that the steady part of the flow is largely dominant. Details in estimating (11) and its caveats are discussed in Read et al. (1986) and in appendix B.

Focusing on smaller regions along the IWBC path, different values of $I$ occur according to the flow characteristics: We see values in the Cape São Tomé region higher than in the recirculation and in the main channel, which is explained by the rich and frequent meandering activity of the IWBC that adds perturbation terms and weakens the mean flow (da Silveira et al. 2008). This also implies that the flow in the vicinity of Tubarão Bight is steadier $(I=0.05$, not shown $)$.

The $\bar{\psi}-\bar{Q}$ scatterplot also sheds light on the stability of nonparallel flows such as the IWBC (Read et al. 1986). In particular, the flow is stable if $d \bar{Q} / d \bar{\psi}>0$ (Arnold's theorem; e.g., Blumen 1968; Read et al. 1986). Figure 7 shows that $\bar{\psi}$ and $\bar{Q}$ are negatively correlated, and thus the flow is potentially unstable.

So far, we have shown that the time-mean IWBC is representative of the steady state, although instabilities may be present. Hence, we shall ask: do local conversions account for all the variability? Or is the variability driven by remote forcing? We next address these questions, using a detailed analysis of the energetics of the eddy-mean flow interactions of the IWBC.

TABLE 2. Main terms from the eddy energy conservation equations: $\mathbf{u}=(u, v, w)$ is the velocity vector, $\nabla$ is the gradient operator, $\Psi$ is the horizontal streamfunction, $N^{2}$ is the buoyancy frequency, $p$ is pressure, and $b$ is buoyancy. Subscripted indices indicate derivatives.

\begin{tabular}{lll}
\hline \hline Term & \multicolumn{1}{c}{ Mathematical form } \\
\hline HSP & $\left(\overline{\tilde{v}^{2}-\tilde{u}^{2}}\right) \psi_{x y}+\overline{\tilde{u} \tilde{v}}\left(\psi_{x x}-\psi_{y y}\right)$ & Effects \\
VSP & $\overline{\tilde{u} \tilde{w}} \bar{u}_{z}+\tilde{\tilde{v} \tilde{w}} \bar{v}_{z}$ & Horizontal shear production \\
HBP & $\left(1 / N^{2}\right)\left(\overline{\tilde{u} \tilde{b}} \bar{b}_{x}+\overline{\tilde{v} \tilde{b}} \bar{b}_{y}\right)$ & Vertical shear production \\
VBP & $\left(1 / N^{2}\right) \overline{\tilde{w} \tilde{b}} \bar{b}_{z}$ & Horizontal buoyancy production \\
$\tilde{w} \tilde{b}$ & $\tilde{w} \tilde{b}$ & Vertical buoyancy production \\
$\nabla \cdot \mathbf{F}_{e}$ & $\nabla \cdot(1 / 2) \overline{\mathbf{u}\left(\tilde{u}^{2}+\tilde{v}^{2}\right)}$ & Vertical buoyancy flux \\
$\nabla \cdot \mathbf{P}_{w}$ & $\nabla \cdot \tilde{u} \tilde{p}$ & Redistribution of $K$ through advection \\
$\nabla \cdot \mathbf{G}_{e}$ & $\nabla \cdot\left(\overline{\mathbf{u} \tilde{b}^{2}} / 2 N^{2}\right)$ & Redistribution of $K$ through pressure work \\
\hline
\end{tabular}




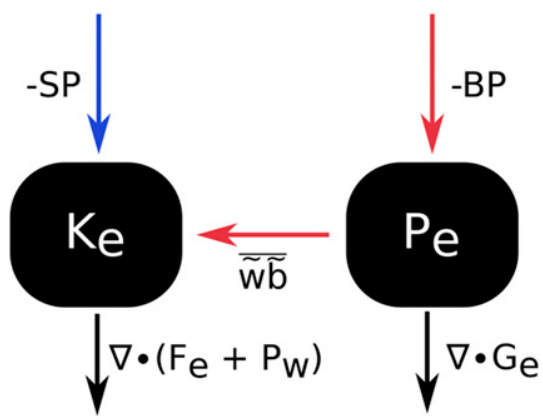

FIG. 8. The modified Lorenz energy diagram focusing on eddy components of the eddy-mean flow interactions. The blue arrow indicates the barotropic instability pathway, red arrows indicate the baroclinic instability pathway, and black arrows represent the redistribution of energy through the borders of the domain. The terms are as follows: $\mathrm{SP} \stackrel{\text { def }}{=}(\overline{\mathrm{HSP}}+\overline{\mathrm{VSP}})$, shear production; $\mathrm{BP} \stackrel{\text { def }}{=}(\overline{\mathrm{HBP}}+\overline{\mathrm{VBP}})$, buoyancy production; $\tilde{w} \tilde{b}$, vertical buoyancy flux; $\mathbf{F}_{e}$, kinetic energy advection; $\mathbf{P}_{w}$, pressure work; and $\mathbf{G}_{e}$, potential energy advection.

\section{Energetics of the eddy-mean flow interaction}

We follow Vallis (2017) in performing a standard eddy-mean flow interaction analysis. The dynamical fields are decomposed into mean and eddy components:

$$
\theta(x, y, z, t)=\bar{\theta}(x, y, z, \bar{t})+\tilde{\theta}(x, y, z, t) .
$$

Here, the overbar denotes an average over fast time, so $\bar{\theta}$ varies on a slow time; operationally, we use a low-pass frequency filter of 60 days.

The total mechanical energy $E_{T}$ is the sum of four components

$$
E_{T}=P_{m}+P_{e}+K_{m}+K_{e}
$$

where

$$
P_{e} \stackrel{\text { def }}{=} \frac{\tilde{b}^{2}}{2 N^{2}} \quad \text { and } \quad K_{e} \stackrel{\text { def }}{=} \frac{1}{2}\left(\tilde{u}^{2}+\tilde{v}^{2}\right),
$$

are the eddy available potential energy and the eddy kinetic energy. Above, $(u, v)$ is the horizontal velocity, $b \stackrel{\text { def }}{=}-g \rho / \rho_{0}$ is the buoyancy, and $N$ is the Brünt-Väisälä frequency. The mean available potential energy $P_{m}$ and kinetic energy $K_{m}$ are defined analogously to (14).

In oceanography, we must use density (buoyancy) to calculate the potential energy budget, especially in cases where salinity plays a major role in the fluid density, as in the AAIW. The potential energy above is only an exact definition for constant $N^{2}$ (Huang 2005).

\section{a. Energy conservation equations}

Redistribution of energy across the eddy-mean reservoirs occurs through processes of barotropic, baroclinic,


FIG. 9. (a) Horizontal shear production. Positive values indicate conversion from $K_{m}$ to $K_{e}$ due to barotropic instability processes. (b) Horizontal buoyancy production. Positive values indicate conversion from $P_{m}$ to $P_{e}$ due to baroclinic instability processes. In both panels arrows represent the mean model velocity.

and mixed instability (Gill et al. 1974; Hart 1974). The eddy kinetic energy and eddy potential energy conservation equations are given by

$$
\begin{aligned}
& \overline{\partial_{\bar{t}} K_{e}}+\nabla \cdot\left(\mathbf{F}_{e}+\mathbf{P}_{w}\right)=-\overline{\mathrm{HSP}}-\overline{\mathrm{VSP}}+\overline{\tilde{w} \tilde{b}}, \\
& \overline{\partial_{\tilde{t}} P_{e}}+\nabla \cdot \mathbf{G}_{e} \approx-\overline{\mathrm{HBP}}-\overline{\mathrm{VBP}}-\overline{\tilde{w} \tilde{b}} .
\end{aligned}
$$

Equations (15) and (16) are the budgets most relevant to our discussion below; Table 2 contains a detailed description of each term. For a derivation of these energy budgets see, for example, Vallis (2017).

The time-varying budgets on the left side of (15) and (16) depend on the balance between the divergence of energy at the boundaries of the domain and the local energy production on their right-hand sides. The conversion terms on the right quantify the transformations between the different forms of energy. The terms SP $\stackrel{\text { def }}{=}$ $(\overline{\mathrm{HSP}}+\overline{\mathrm{VSP}})$ are associated with shear instabilities, 

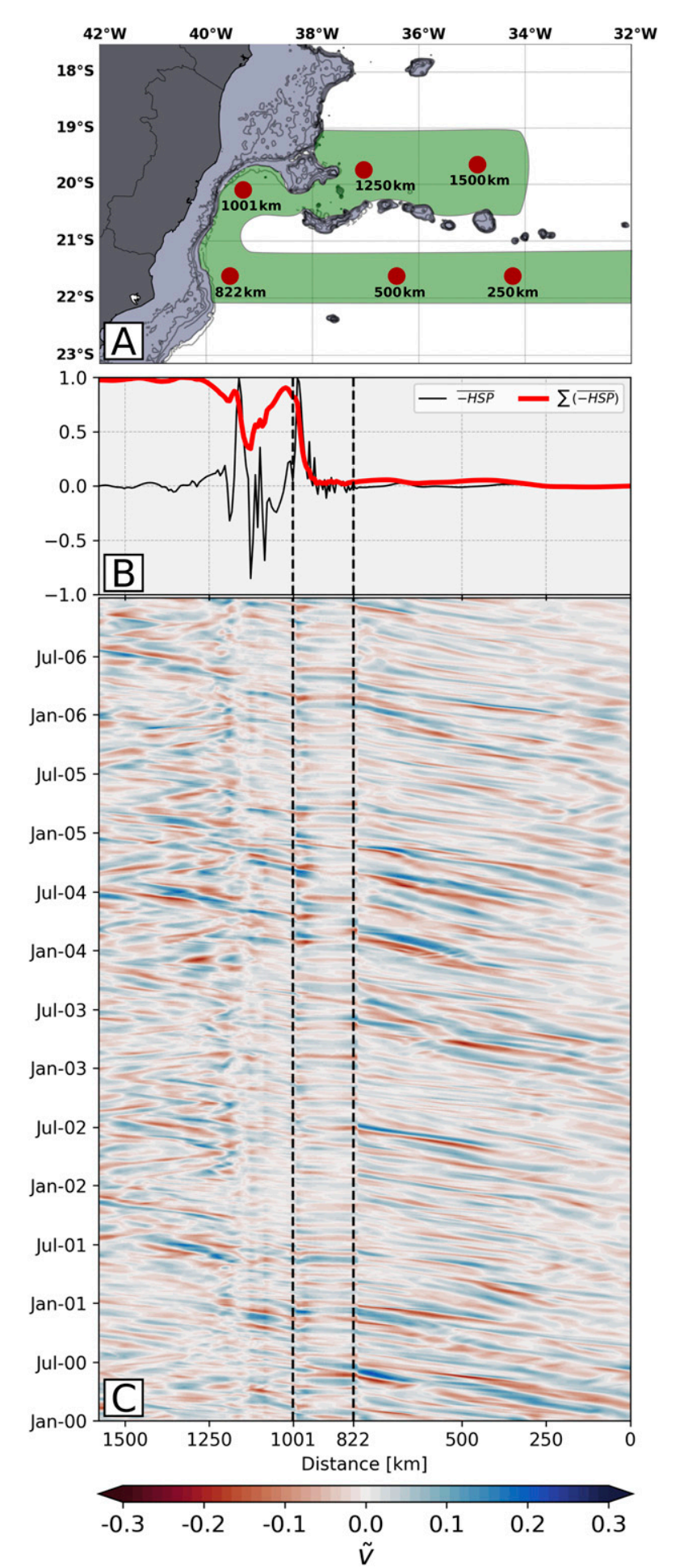

FIG. 10. (a) Hovmöller diagram path including the zonal transect at $22^{\circ} \mathrm{S}$, the IWBC path within Tubarão Bight, and a $19.5^{\circ} \mathrm{S}$ transect north of the Vitória-Trindade Ridge. We averaged $\tilde{v}$ within this $22^{\circ} \mathrm{S}-\mathrm{IWBC}-19.5^{\circ} \mathrm{S}$ path to capture different trajectories followed by perturbations advected by the IWBC. (b) Horizontal shear production (HSP) and cumulative HSP along the $22^{\circ} \mathrm{S}-\mathrm{IWBC}-$ $19.5^{\circ} \mathrm{S}$ path. Positive (negative) values in HSP indicate mean-eddy and the $\mathrm{BP} \stackrel{\text { def }}{=}(\overline{\mathrm{HBP}}+\overline{\mathrm{VBP}})$ terms are associated with eddy buoyancy fluxes (e.g., Chen et al. 2014). The vertical buoyancy flux $\tilde{w} \tilde{b}$ associated with the energy pathway $P_{m} \rightarrow P_{e} \rightarrow K_{e}$ is a telltale signal of baroclinic instability processes (e.g., Pedlosky 1987). These processesamong others detailed below-are represented here in an eddy-focused version of the traditional Lorenz diagram (Fig. 8).

The flux divergence terms $\mathbf{G}_{e}, \mathbf{F}_{e}$, and $\mathbf{P}_{w}$ account for the redistribution of eddy energy through advection and pressure work. Although not computed explicitly, the residual term that represents horizontal and vertical mixing, heat and freshwater fluxes, wind forcing, and bottom drag is included to close the energy balance (Chen et al. 2014).

We calculate energy budgets in the IWBC using ROMS daily outputs to estimate the conversion and redistribution terms in Table 2 . We vertically average ROMS fields within the AAIW layer (1027.1-1027.4 $\mathrm{kg} \mathrm{m}^{-3}$; Tsuchiya et al. 1994) and apply the decomposition (12) to the resulting 2D fields (terms with $z$ dependence are calculated prior to averaging). We define the eddy component as variability with time scales shorter than 60 days.

\section{b. Energy conversions}

Existing studies of the BC-IWBC system energetics focused on regions south of the VTR, restricted either to Cape São Tomé and Cape Frio (e.g., Mano et al. 2009) or to southeast Brazil (e.g., Oliveira et al. 2009; Magalhães et al. 2017). Those studies showed that baroclinic conversions account for most of the eddy generation, though barotropic conversions may be important in some regions.

Here, both barotropic and baroclinic conversions are at play (see Fig. 9). In particular, barotropic conversion through horizontal shear production (HSP) is larger where the IWBC splits into two branches near the exit from Tubarão Bight and off the Abrolhos Bank (see Fig. 9a). Baroclinic conversion, through horizontal buoyancy production (HBP), is also enhanced north of the VTR; HSP is twice as large as HBP. Vertical conversions, through vertical shear production (VSP) and vertical buoyancy production (VBP), are small over most of the region but large near seamounts, becoming important in the energy budget of subregions such as Tubarão Bight. In the ocean, this is associated with enhanced vertical mixing (e.g., Polzin et al. 1997).

$\leftarrow$

(eddy-mean) kinetic energy conversion. (c) Hovmöller diagram of $\tilde{v}$ along the $22^{\circ} \mathrm{S}-\mathrm{IWBC}-19.5^{\circ} \mathrm{S}$ path. Tilted crests and troughs indicate propagation of perturbations. Dashed lines at $822 \mathrm{~km}$ and $1001 \mathrm{~km}$ show the limits of Tubarão Bight. 

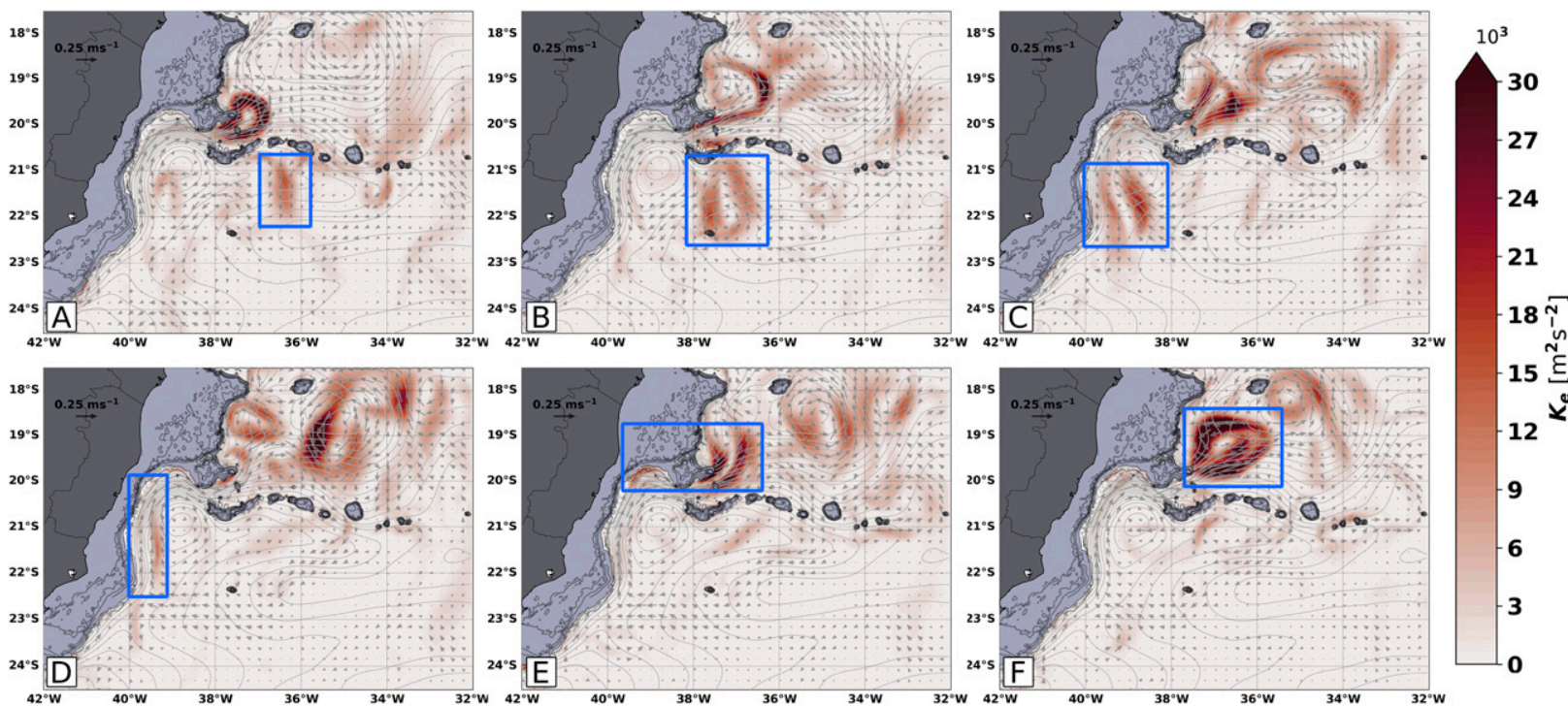

FIG. 11. Tracking of a wavelike perturbation (highlighted by the blue rectangle) entering Tubarão Bight and being carried north of the VTR by the IWBC. From the detection of the perturbation at longitude $36^{\circ} \mathrm{W}$ on $5 \mathrm{Jan} 2002$, the panels represent the evolution of the signal at day (a) 1, (b) 25, (c) 56, (d) 71, (e) 81, and (f) 92 . The red shading is $K_{e}$ calculated from ROMS outputs, arrows indicate ROMS daily total velocity, and solid gray lines represent the steady-state streamfunction.

The theoretical analysis of section 3 suggests that the region south of the VTR is prone to instabilities of the IWBC mean flow, yet the energetics of the numerical model in this section show that most conversions occur north of the VTR. To solve this apparent contradiction, we next look into the details of the model output within the Tubarão Bight region.

\section{c. Breaking the steadiness}

Figure 10c shows a Hovmöller diagram of ROMS meridional eddy velocity along the path in Fig. 10a. We average $\tilde{v}$ along this envelope from the easternmost seamount at $\sim 32^{\circ} \mathrm{W}$ to the continental margin at $\sim 40^{\circ} \mathrm{W}$, along the mean IWBC streamline within Tubarão Bight and downstream of the VTR at $19.5^{\circ} \mathrm{S}$. Encompassing a larger area compared to a single path allows us to track perturbations advected by the IWBC, which follow different paths within the Tubarão Bight and grow in distinct regions downstream of the VTR. We also show the horizontal shear production (HSP) and the cumulative HSP along this path in Fig. 10b. Throughout the model time series, tilted alternating velocity patterns indicate perturbations propagating along the $22^{\circ} \mathrm{S}$ path, eventually reaching the continental margin in Tubarão Bight. Quasizonal bands of $\tilde{v}$ between 822 and $1001 \mathrm{~km}$ show a sudden increase in phase velocity as the IWBC advects perturbations downstream of the VTR. Those perturbations trigger eddy-mean flow interactions, mostly by barotropic conversions (Fig. 10b). This interaction mechanism yields mean-to-eddy energy transfers through standard Reynolds-stress horizontal shear production (e.g., Vallis 2017). These results are consistent with those of Mata et al. (2006), which, during eddy-shedding events of the East Australian Current, revealed the downstream growth of perturbations through horizontal shear production.

We track one of the strongest perturbation events in the simulation (Fig. 11). This perturbation is enhanced at $\sim 36^{\circ} \mathrm{W}$ on 1 May 2002 (see Fig. 11a) and propagates westward at $4.47 \mathrm{~km}$ day $^{-1}$. About 25 days after this enhancement at $\sim 36^{\circ} \mathrm{W}$, an anticyclonic structure begins to approach the eastern limit of Tubarão Bight (see Fig. 11b). Within the bight, the ring propagates to the southwest through the time-mean flow; the eddy velocity is perpendicular to the time-mean flow (see vectors and streamlines in Fig. 11c). Once the ring reaches the western boundary, it is strained by the mean flow and quickly advected downstream (see Fig. 11d). The perturbation grows significantly as it crosses the VTR, generating a strong eddy field north of the ridge (Figs. 11e,f). (This sequence of events occurs for most of the perturbations seen in the Hovmöller diagram.) The strong eddy field off the Abrolhos Bank is consistent with the swirly float trajectories reported by Legeais et al. (2013).

We select 29 events from the series and estimate a mean wavelength of $344 \pm 89 \mathrm{~km}$, a mean period of $36 \pm$ 7 days, and a mean phase speed $c=0.06 \pm 0.01 \mathrm{~m} \mathrm{~s}^{-1}$ $\left(5.18 \mathrm{~km} \mathrm{day}^{-1}\right)$. The mean eddy speed is $|\mathbf{u}|=0.07 \pm$ $0.03 \mathrm{~m} \mathrm{~s}^{-1}\left(6.05 \mathrm{~km} \mathrm{day}^{-1}\right)$, so $|\mathbf{u}| / c \approx 1.14 \pm 0.57$, suggesting nonlinearity (Chelton et al. 2011). We show that these nonlinear westward-propagating eddies have Eulerian 




FIG. 12. (a) Rossby wave dispersion relation diagram for Tubarão Bight. The thick black line represents the linear first-mode Rossby wave dispersion relation (deformation radius $\cong 70 \mathrm{~km}$ ). The second and third modes are plotted with thinner lines (deformation radius $\cong 35$ and $20 \mathrm{~km}$, respectively). The dashed red line represents the nondispersive line (NDL) for the first-mode waves. The blue stars indicate the characteristics based on the Eulerian phase speeds of the signals tracked. (b) Vertical $\tilde{v}$ structure of the signal on 30 Jan 2002. (c) Reconstruction of the signal using the first baroclinic mode. (d) Reconstruction of the signal using the barotropic and the first three baroclinic modes.

phase speeds consistent with the nondispersive linear Rossby-wave dispersion relation (Fig. 12a), as previously remarked by Morten et al. (2017). A standard modal analysis of these subsurface-intensified eddies indicates that the first baroclinic mode accounts for most of the variance, about $40 \%$. And a synthesis with the gravest four modes accounts for $80 \%$ of the eddy vertical structure (Figs. 12b-d).

\section{d. Tubarão Bight energetics}

We now turn to the energy budget in Tubarão Bight, defined as the $\sim 19-23^{\circ} \mathrm{S}$ domain west of $\sim 36^{\circ} \mathrm{W}$. For this region, we calculate the energy conversion terms and the energy fluxes in Table 2. Figures $13 a-c$ show in colors the total eddy kinetic energy generation, $-\overline{\mathrm{SP}}+\overline{\tilde{w}} \tilde{b}$, and arrows indicate the kinetic energy flux $\mathbf{F}_{e}$ and pressure-work flux $\mathbf{P}_{w}$ through the boundaries. Kinetic energy enters the domain through pressure work and advection by the mean flow, mostly across the southeastern corner. This eddy energy is advected northward through the VTR by the IWBC mean flow. North of the VTR, copious eddy kinetic energy is generated by barotropic conversion $-\langle\mathrm{HSP}\rangle$. The enhanced eddy kinetic energy is advected northeastward 

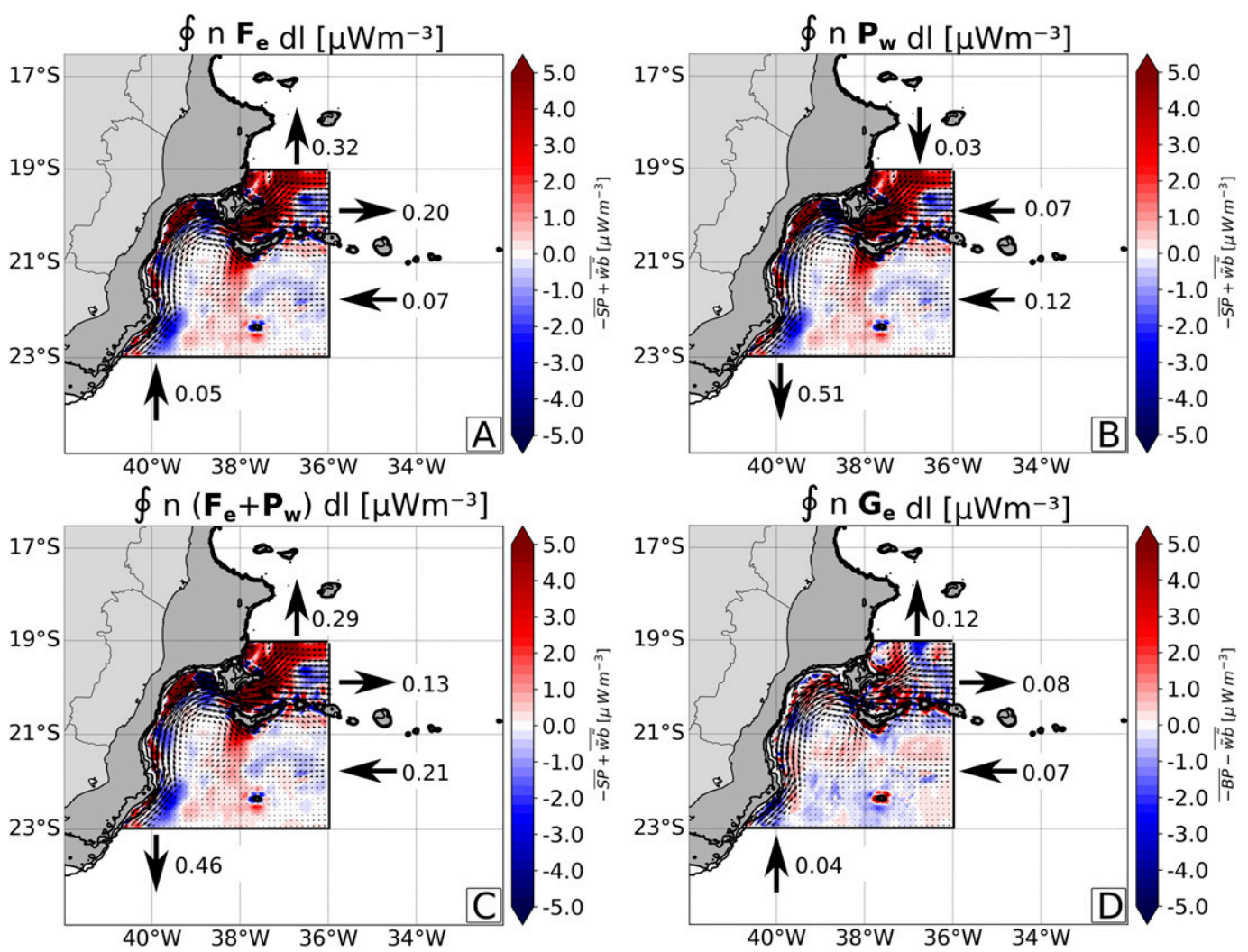

FIG. 13. Divergence at the Tubarão Bight borders of (a) $K_{e}$ advection, (b) pressure work, (c) $K_{e}$ advection plus pressure work, and (d) potential energy advection. Arrows represent flow through the borders, indicating a source (sink) of energy when the arrow points to the inside (outside) of the region.

out of the domain or propagates southward through pressure work.

The dominant eddy kinetic energy budget within Tubarão Bight is

$$
\langle\mathrm{HSP}\rangle \approx \oint \mathbf{n} \cdot \mathbf{F}_{e} d l+\oint \mathbf{n} \cdot \mathbf{P}_{w} d l .
$$

In other words, the eddy kinetic energy flux (mostly through advection by the mean flow) and the pressure work balance horizontal shear production within Tubarão Bight (see detailed energy budget in Fig. 14). Perturbations enter the domain through the southeastern boundary through $\mathbf{P}_{w}$ and $\mathbf{F}_{e}$, are advected through the VTR by the IWBC, and then grow explosively downstream of the ridge through horizontal shear production.

For completeness, we also present the eddy potential energy budget in Figs. 13d and 15. The dominant budget is

$$
\langle\mathrm{VBP}\rangle+\langle\overline{\tilde{w} \tilde{b}}\rangle \approx \oint \mathbf{n} \cdot \mathbf{G}_{e} d l .
$$

Eddy potential energy is advected into the domain mostly by the mean flow across the southern and southeastern boundaries. Within Tubarão Bight, eddy potential energy is generated by vertical buoyancy production, particularly near seamounts, and via conversions from the eddy kinetic energy reservoir through buoyancy flux $-\langle\tilde{w} \tilde{b}\rangle$. The eddy potential energy generated within Tubarão Bight is advected out of the region by the mean flow across the northern and northeastern boundaries.

In summary, the energetics suggest that westwardpropagating features, such as the one in Fig. 11, interact with the mean flow as they are advected by the IWBC, experiencing explosive growth downstream of the VTR. The mechanism of interaction is barotropic conversions, and the process appears to be constrained by topography. A simple representation of the Tubarão Bight energy budget is shown in Fig. 16.

\section{Final remarks}

New direct velocity measurements of the Intermediate Western Boundary Current (IWBC) show (and detail) a circulation pattern consistent with the existing literature, namely, (i) off Cape São Tomé, the IWBC 


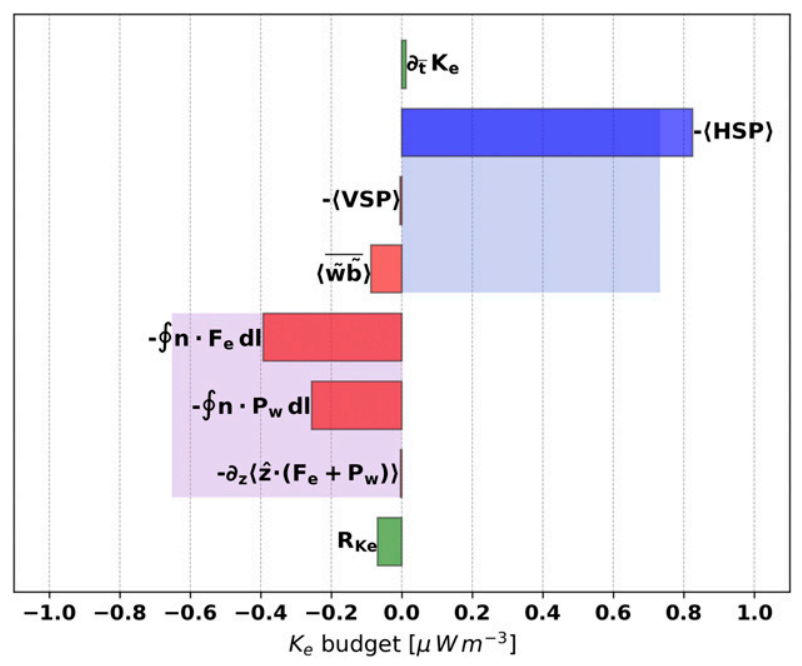

FIG. 14. The kinetic energy budget for Tubarão Bight according to Eq. (15). Blue/positive (red/negative) bars represent a source (sink) of energy. Green bars indicate the residuals of the timevarying $K_{e}$. Residuals are from $\sim 9 \%$ to close $99 \%$ of the budget.

flows northward along the continental slope, underneath the southward-flowing Brazil Current; (ii) at Tubarão Bight, topography steers the IWBC, generating a cyclonic recirculation that intensifies the flow along the continental slope south of the bight; and (iii) the remaining IWBC flow exits the bight through the VitóriaTrindade Ridge main channel. Argo float trajectories reveal a larger, zonally elongated IWBC recirculation around the VTR that extends to $\sim 35^{\circ} \mathrm{W}$. A regional simulation with ROMS shows good skill in simulating these observational patterns, including the IWBC recirculation cells.

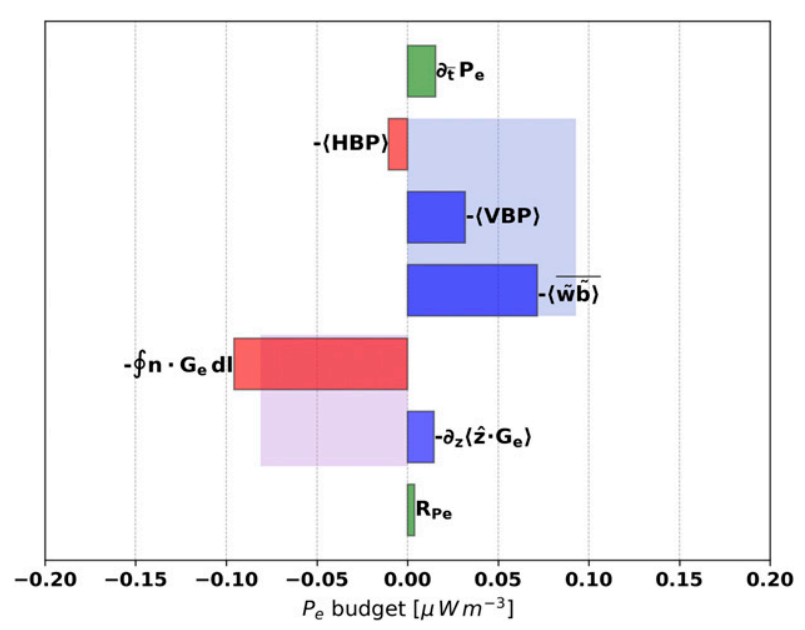

FIG. 15. The potential energy budget for Tubarão Bight according to Eq. (16). Blue/positive (red/negative) bars represent a source (sink) of energy. Green bars indicate the residuals of the timevarying $P_{e}$. Residuals are from $\sim 3 \%$ to close $87 \%$ of the budget.

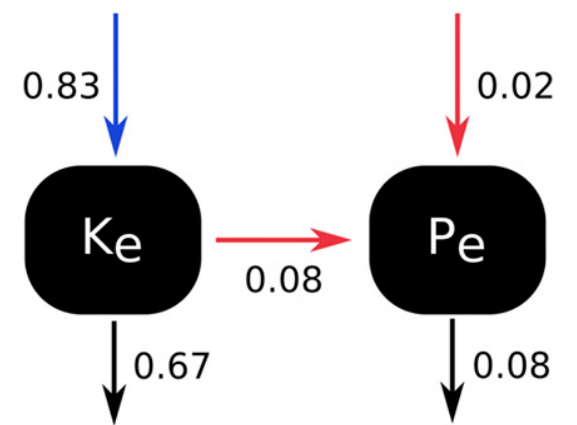

FIG. 16. The Tubarão Bight energy budget $\left(\mu \mathrm{Wm}^{-3}\right)$ represented by the Lorenz energy diagram. Blue lines indicate the barotropic instability pathway, red lines indicate the baroclinic instability pathway, and black lines represent the redistribution of energy through the borders of the domain.

Analysis of an intermediate-layer QG model shows that the time-mean ROMS circulation is a good proxy for the IWBC steady state $(>90 \%)$, with the linear inversion relation $\bar{Q}=-3.84 \times 10^{-9} \bar{\psi}$. And geostrophic scatterplots suggest that the IWBC is unstable along its path $(d \bar{\psi} / d \bar{Q}<0)$.

Despite a steadiness indicated by the QG analysis, ROMS eddy-mean energy exchanges are important throughout the model domain. A detailed energy analysis around Tubarão Bight shows that steadiness is broken by nonlinear eddies that enter the domain through the eastern boundary. Despite their nonlinearity, these eddies have phase speeds consistent with nondispersive linear Rossby-wave theory. The perturbations interact with the IWBC mean flow via barotropic conversions. As they are advected downstream, the eddies grow by feeding off the mean flow through standard Reynoldsstress horizontal shear production, with topography seemly playing an important role in this growth process.

The model results highlight the complexity of the eddy-mean flow interactions off east Brazil, with both remote forcing and downstream eddy growth playing critical roles. Process-oriented observational studies are needed to test these model predictions and further characterize local and nonlocal eddies in this region and their effects on the IWBC and the Meridional Overturning Circulation.

Acknowledgments. We thank Frank O. Smith for copy editing and proofreading this manuscript. This study was financed in part by Coordenação de Aperfeiçoamento de Pessoal de Nível Superior-CAPES, Brazil-Finance Code 001 and by Projeto REMARSUL (Processo CAPES 88882.158621/2014-01), Projeto VT-Dyn (Processo FAPESP 2015/21729-4) and Projeto SUBMESO (Processo CNPq 442926/2015-4). Rocha was supported by a WHOI Postdoctoral Scholarship. 


\section{APPENDIX A}

\section{Calculation of $g^{\prime}$}

In the model schematic presented in section 3, layer thickness $h=h(x, y)$ is a function of space only, and density is constant for each layer. We evaluate the pressure in the upper layer $P_{1}=\rho_{1} g\left(h_{1}+h+h_{2}-z\right)$ and at $z=0$ in the bottom layer $P_{2}(x, y, 0)=\rho_{1} g h_{1}+$ $\rho g h+\rho_{2} g h_{2}$. Setting the horizontal gradient of both to zero gives

$$
\begin{array}{r}
\nabla h_{2}+\nabla h+\nabla h_{1}=0, \\
\rho_{2} \nabla h_{2}+\rho \nabla h+\rho_{1} \nabla h_{1}=0,
\end{array}
$$

which can be solved to relate the height gradients above and below to $\nabla h$ :

$$
\nabla h_{2}=-\left(\frac{\rho_{1}-\rho}{\rho_{2}-\rho_{1}}\right) \nabla h \quad \text { and } \quad \nabla h_{1}=\left(\frac{\rho-\rho_{2}}{\rho_{2}-\rho_{1}}\right) \nabla h .
$$

We can find the pressure $P$ in the middle layer by integrating from the bottom, with $P_{2}$ the (constant) pressure at a horizontal surface $z=0$ deep within the layer:

$$
P=P_{2}-\rho_{2} g h_{2}-\rho g\left(z-h_{2}\right) \text {. }
$$

Taking the horizontal gradient of (A3) and replacing $\nabla h_{2}$ from (A2) yields

$$
\frac{\nabla P}{\rho}=g\left(\frac{\rho-\rho_{1}}{\rho_{2}-\rho_{1}}\right)\left(\frac{\rho_{2}-\rho}{\rho}\right) \nabla h=g^{\prime} \nabla h,
$$

so that $g^{\prime}$ is given by

$$
g^{\prime}=g\left(\frac{\rho-\rho_{1}}{\rho_{2}-\rho_{1}}\right)\left(\frac{\rho_{2}-\rho}{\rho}\right)
$$

\section{APPENDIX B}

\section{Estimation of Scatter Cloud Relative Area}

In $\psi-Q$ space, the scatter of points about the line correlating the variables represents the amount of departure from free mode in a flow. From

$$
I \stackrel{\text { def }}{=} \frac{A}{\Delta \Psi \Delta Q}=\frac{\text { Area enclosed by the cloud of points }}{\text { Area of the rectangle }},
$$

the area $A$ was estimated from a polygon drawn graphically connecting values of $Q_{\min }$ and $Q_{\max }$ in a given $\partial \Psi$, as in Fig. B1.

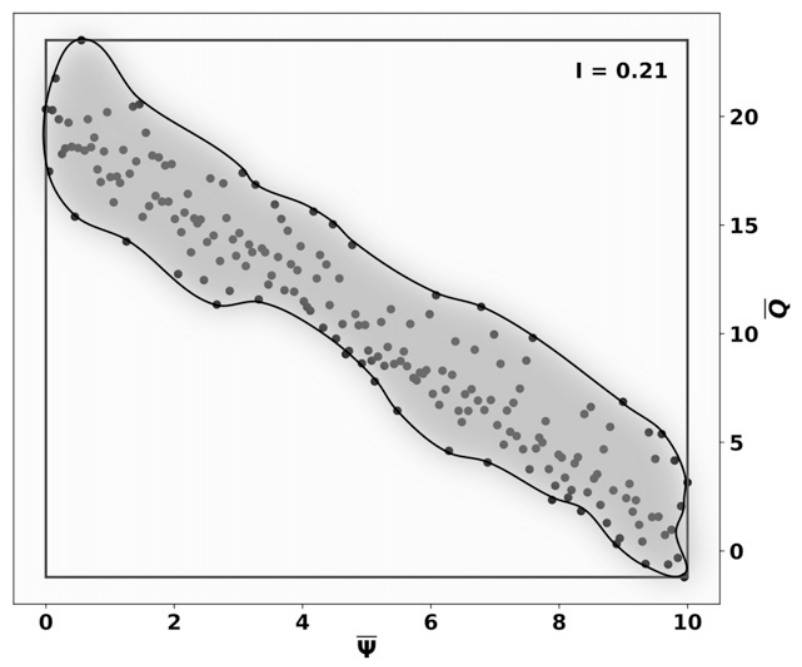

FIG. B1. Representation of a random cloud of points in $\Psi-Q$ space and the area around it, occupying $21 \%$ of the maximum area delimited by the $\Delta \Psi \Delta Q$ rectangle.

In a high-resolution grid filling the rectangle $\Delta \Psi \Delta Q$, the area $A$ enclosed by the cloud of points can be interpreted as the number of points inside the hatched polygon. In the illustrative example,

$$
I=\frac{210000}{1000 \times 1000}=0.21,
$$

thus implying $79 \%$ correlation within this fictional dataset.

Read et al. (1986) discuss the caveats of this index, which depends on the orientation of the polygon, as well as on its shape in $\psi-Q$ space. The authors also propose an alternative metric based on the perpendicular width of the scatter cloud relative to its length: given a scatter cloud angle $\phi \leq \pi / 2$, the width-to-length ratio is thus $\tan (\phi) / 2$ and a measure of the departure from free mode. For the IWBC, this metric yields $\sim 0.15$, against 0.08 of the $I$ index.

\section{REFERENCES}

Argo, 2019: Argo float data and metadata from Global Data Assembly Centre (Argo GDAC). SEANOE, https://doi.org/ $10.17882 / 42182$.

Biló, T. C., I. C. A. da Silveira, W. C. Belo, B. M. Castro, and A. R. Piola, 2014: Methods for estimating the velocities of the Brazil Current in the pre-salt reservoir area off southeast Brazil (23ํ S-26 ${ }^{\circ}$ S). Ocean Dyn., 64, 1431-1446, https://doi.org/10.1007/ s10236-014-0761-2.

Blumen, W., 1968: On the stability of quasi-geostrophic flow. J. Atmos. Sci., 25, 929-931, https://doi.org/10.1175/1520-0469(1968) 025<0929:OTSOQG $>2.0$. CO;2.

Boebel, O., C. Schmid, and W. Zenk, 1997: Flow and recirculation of Antarctic Intermediate Water across the Rio Grande rise. 
J. Geophys. Res., 102, $20967-20986$, https://doi.org/10.1029/ 97JC00977.

, R. Davis, M. Ollitrault, R. Peterson, P. Richardson, C. Schmid, and W. Zenk, 1999: The intermediate depth circulation of the western South Atlantic. Geophys. Res. Lett., 26, 3329-3332, https://doi.org/10.1029/1999GL002355.

Bretherton, F. P., and D. B. Haidvogel, 1976: Two-dimensional turbulence above topography. J. Fluid Mech., 78, 129-154, https://doi.org/10.1017/S002211207600236X.

Campos, E. J., 2006: Equatorward translation of the Vitória Eddy in a numerical simulation. Geophys. Res. Lett., 33, L22607, https://doi.org/10.1029/2006GL026997.

Chelton, D. B., M. G. Schlax, and R. M. Samelson, 2011: Global observations of nonlinear mesoscale eddies. Prog. Oceanogr., 91, 167-216, https://doi.org/10.1016/j.pocean.2011.01.002.

Chen, R., G. R. Flierl, and C. Wunsch, 2014: A description of local and nonlocal eddy-mean flow interaction in a global eddypermitting state estimate. J. Phys. Oceanogr., 44, 2336-2352, https://doi.org/10.1175/JPO-D-14-0009.1.

Costa, V. S., G. N. Mill, M. Gabioux, G. S. Grossmann-Matheson, and A. M. Paiva, 2017: The recirculation of the intermediate western boundary current at the Tubarão Bight-Brazil. DeepSea Res. I, 120, 48-60, https://doi.org/10.1016/j.dsr.2016.12.001.

da Silveira, I. C. A., and G. R. Flierl, 2002: Eddy formation in 21/2layer, quasigeostrophic jets. J. Phys. Oceanogr., 32, 729-745, https://doi.org/10.1175/1520-0485(2002)032<0729:EFILQJ> 2.0.CO;2.

, L. Calado, B. Castro, M. Cirano, J. Lima, and A. S. Mascarenhas, 2004: On the baroclinic structure of the Brazil Current-Intermediate Western Boundary Current system at $22^{\circ}-23^{\circ}$ S. Geophys. Res. Lett., 31, L14308, https://doi.org/ 10.1029/2004GL020036.

, J. Lima, A. Schmidt, W. Ceccopieri, A. Sartori, C. Franscisco, and R. Fontes, 2008: Is the meander growth in the Brazil Current system off Southeast Brazil due to baroclinic instability? Dyn. Atmos. Oceans, 45, 187-207, https://doi.org/10.1016/ j.dynatmoce.2008.01.002.

Evans, D. L., and S. S. Signorini, 1985: Vertical structure of the Brazil Current. Nature, 315, 48-50, https://doi.org/10.1038/315048a0.

- S. R. Signorini, and L. B. Miranda, 1983: A note on the transport of the Brazil Current. J. Phys. Oceanogr., 13, 1732-1738, https://doi.org/10.1175/1520-0485(1983)013<1732:ANOTTO> 2.0.CO;2

Firing, E., J. Ranada, and P. Caldwell, 1995: Processing ADCP data with the CODAS software system version 3.1. Tech. Doc., 218 pp.

Gill, A., J. Green, and A. Simmons, 1974: Energy partition in the large-scale ocean circulation and the production of mid-ocean eddies. Deep-Sea Res. Oceanogr. Abstr., 21, 499-528, https:// doi.org/10.1016/0011-7471(74)90010-2.

Hart, J., 1974: On the mixed stability program for quasigeostrophic ocean currents. J. Phys. Oceanogr., 4, 349-356, https://doi.org/10.1175/1520-0485(1974)004<0349:OTMSPF> 2.0.CO;2

Huang, R. X., 2005: Available potential energy in the world's oceans. J. Mar. Res., 63, 141-158, https://doi.org/10.1357/ 0022240053693770.

Isern-Fontanet, J., B. Chapron, G. Lapeyre, and P. Klein, 2006: Potential use of microwave sea surface temperatures for the estimation of ocean currents. Geophys. Res. Lett., 33, L24608, https://doi.org/10.1029/2006GL027801.

Lebedev, K. V., H. Yoshinari, N. A. Maximenko, and P. W. Hacker, 2007: Velocity data assessed from trajectories of
Argo floats at parking level and at the sea surface. IPRC Tech. Note 4(2), 16 pp., http://apdrc.soest.hawaii.edu/projects/yomaha/ yomaha07/YoMaHa070612.pdf.

Legeais, J.-F., M. Ollitrault, and M. Arhan, 2013: Lagrangian observations in the intermediate western boundary current of the South Atlantic. Deep-Sea Res. II, 85, 109-126, https://doi.org/ 10.1016/j.dsr2.2012.07.028.

Lima, M. O., M. Cirano, M. M. Mata, M. Goes, G. Goni, and M. Baringer, 2016: An assessment of the Brazil Current baroclinic structure and variability near $22^{\circ} \mathrm{S}$ in Distinct Ocean Forecasting and Analysis Systems. Ocean Dyn., 66, 893-916, https://doi.org/10.1007/s10236-016-0959-6.

Magalhães, F. C., J. L. L. Azevedo, and L. R. Oliveira, 2017: Energetics of eddy-mean flow interactions in the Brazil Current between $20^{\circ} \mathrm{S}$ and $36^{\circ} \mathrm{S}$. J. Geophys. Res. Oceans, 122, 6129-6146, https://doi.org/10.1002/2016JC012609.

Mano, M. F., A. M. Paiva, A. R. Torres Jr., and A. L. Coutinho, 2009: Energy flux to a cyclonic eddy off Cabo Frio, Brazil. J. Phys. Oceanogr., 39, 2999-3010, https://doi.org/10.1175/ 2009JPO4026.1.

Mata, M. M., S. E. Wijffels, J. A. Church, and M. Tomczak, 2006: Eddy shedding and energy conversions in the East Australian Current. J. Geophys. Res., 111, C09034, https://doi.org/10.1029/ 2006JC003592.

- - M. Cirano, M. R. van Caaspel, C. Fonteles, G. Goni, and M. Baringer, 2013: Observations of the Brazil Current baroclinic transportation near $22^{\circ} \mathrm{S}$ : Variability from the AX97 XBT transect and satellite altimetry. Proceedings of 20 years of progress in radar altimetry: 24-29 September 2012, Venice, Italy, ESA SP, Vol. 710, European Space Agency, 151.

Morten, A. J., B. K. Arbic, and G. R. Flierl, 2017: Wavenumberfrequency analysis of single-layer shallow-water beta-plane quasi-geostrophic turbulence. Phys. Fluids, 29, 106602, https:// doi.org/10.1063/1.5003846.

Müller, T. J., Y. Ikeda, N. Zangenberg, and L. V. Nonato, 1998: Direct measurements of western boundary currents off Brazil between $20^{\circ} \mathrm{S}$ and $28^{\circ} \mathrm{S}$. J. Geophys. Res., 103, 5429-5437, https://doi.org/10.1029/97JC03529.

Oliveira, L. R., A. R. Piola, M. M. Mata, and I. D. Soares, 2009: Brazil Current surface circulation and energetics observed from drifting buoys. J. Geophys. Res. Oceans, 114, C10006, https://doi.org/10.1029/2008JC004900.

Park, J. J., K. Kim, B. A. King, and S. C. Riser, 2005: An advanced method to estimate deep currents from profiling floats. J. Atmos. Oceanic Technol., 22, 1294-1304, https://doi.org/ 10.1175/JTECH1748.1.

Pedlosky, J., 1987: Geophysical Fluid Dynamics. Springer, 710 pp.

Polzin, K., J. Toole, J. Ledwell, and R. Schmitt, 1997: Spatial variability of turbulent mixing in the abyssal ocean. Science, 276, 93-96, https://doi.org/10.1126/science.276.5309.93.

Read, P., P. Rhines, and A. White, 1986: Geostrophic scatter diagrams and potential vorticity dynamics. J. Atmos. Sci., 43, 3226-3240, https://doi.org/10.1175/1520-0469(1986) 043<3226:GSDAPV>2.0.CO;2.

Rintoul, S. R., 1991: South Atlantic interbasin exchange. J. Geophys. Res., 96, 2675-2692, https://doi.org/10.1029/90JC02422.

Rocha, C. B., I. C. da Silveira, B. M. Castro, and J. A. M. Lima, 2014: Vertical structure, energetics, and dynamics of the Brazil Current System at $22^{\circ} \mathrm{S}-28^{\circ} \mathrm{S}$. J. Geophys. Res. Oceans, 119 , 52-69, https://doi.org/10.1002/2013JC009143.

Schmid, C., and S. L. Garzoli, 2009: New observations of the spreading and variability of the Antarctic Intermediate Water 
in the Atlantic. J. Mar. Res., 67, 815-843, https://doi.org/ $10.1357 / 002224009792006151$.

- , and S. Majumder, 2018: Transport variability of the Brazil Current from observations and a data assimilation model Ocean Sci., 14, 417-436, https://doi.org/10.5194/os-14-417-2018.

—, G. Siedler, and W. Zenk, 2000: Dynamics of intermediate water circulation in the subtropical South Atlantic. J. Phys. Oceanogr., 30, 3191-3211, https://doi.org/10.1175/1520-0485(2000) 030<3191:DOIWCI $>2.0$. CO 2 .

Schmitz, W. J., 1995: On the interbasin-scale thermohaline circulation. Rev. Geophys., 33, 151-173, https://doi.org/10.1029/95RG00879.

Soutelino, R. G., I. C. da Silveira, A. A. Gangopadhyay, and J. Miranda, 2011: Is the Brazil Current eddy-dominated to the north of $20^{\circ} \mathrm{S}$ ? Geophys. Res. Lett., 38, L03607, https://doi.org/ 10.1029/2010GL046276.

Stommel, H. M., 1965: The Gulf Stream: A Physical and Dynamical Description. 2nd ed., University of California Press, $248 \mathrm{pp}$.

Stramma, L., Y. Ikeda, and R. G. Peterson, 1990: Geostrophic transport in the Brazil Current region north of 20
S. Deep-Sea Res., 37A, 1875-1886, https://doi.org/10.1016/ 0198-0149(90)90083-8.

Tsuchiya, M., L. D. Talley, and M. S. McCartney, 1994: Water-mass distributions in the western South Atlantic; A section from South Georgia Island (54S) northward across the equator. J. Mar. Res., 52, 55-81, https://doi.org/10.1357/0022240943076759.

Vallis, G. K., 2017: Atmospheric and Oceanic Fluid Dynamics: Fundamentals and Large-Scale Circulation. 2nd ed. Cambridge University Press, 964 pp.

Weatherall, P., and Coauthors, 2015: A new digital bathymetric model of the world's oceans. Earth Space Sci., 2, 331-345, https://doi.org/10.1002/2015EA000107.

Wienders, N., M. Arhan, and H. Mercier, 2000: Circulation at the western boundary of the South and Equatorial Atlantic: Exchanges with the ocean interior. J. Mar. Res., 58, 1007-1039, https://doi.org/10.1357/002224000763485782.

Wüst, G., 1935: The Stratosphere of the Atlantic Ocean. Scientific Results of the German Atlantic Expedition of the Research Vessel "Meteor"'1925-27, Vol. 6, 109-288 (English translation, W. J. Emery, Ed., Amerind, 1978). 